\title{
PERBEDAAN PENGETAHUAN, SIKAP DA TINDAKAN IBU SESUDAH MENDAPATKAN BOOKLET PENDIDIKAN SEKSUAL UNTUK ANAK USIA DINI
}

\author{
Dyah Triwidiyantari \\ Program Pascasarjana Magister Kebidanan Fakultas Kedokteran \\ Universitas Padjadjaran \\ E-mail: dyahtriwidiyantari@gmail.com \\ Elsa Pudji Setiawati \\ Departemen Ilmu Kesehatan Masyarakat, Fakultas \\ Kedokteran Universitas Padjadjaran \\ E-mail: elsapudjisetiawati@gmail.com \\ Ahmad Rizal Ganiem \\ Departemen Neurologi Rumah Sakit Hasan Sadikin Bandung \\ E-mail:ahmadrizal@gmail.com
}

Article received: 28 Agustus 2019, Review process: 29 Agustus 2019

Article published: 30 September 2019

\begin{abstract}
Information about sexuality these chareges in the future you would better get off the child directly from their parents, however because a lack of knowledge on the part of parents and the lack of the interaction of and a communication between of parents and children would be the main factor has not yet been sexual education will be made as early in its scope the family. Information on sexual health that is given to them nor in a son of aims to get the child does not have an understanding that is erroneous and there were two sexual harassment user to become a victim. To be able to increase of knowledge a gradual mother required approach education health a printing press regional level work unit containing sexual latest booklet education information for their first three children in early childhood education which are presented in from a written note and pictures so as to be easily considered to be too difficult and the message can be enjoyed anytime without specifies the time. This research is a study pree-eksperimen using a design one group pretest-posttest, was done in urban villages kebon waru the working areas of the city of Bandung and used a samples from 34 women in the later stages with children of 3-6 years of age or who were chosen with a concecutive the sampling method. The level of knowledge of, the attitudes and the act of mother after get education latest booklet sexual in early childhood education measured using a questionnaire. The data analysis by test Wilcoxon. The results of studies show there is a significant difference with the value of $p<0,05$ with increased $30 \%$ on the


score knowledge before and after granting treatment by. Booklets On the score attitude there is an increase of 11,42\% with value $p<0,05$ means there is a significant difference between without being granted treatment by after he received treatment by. Booklets By the experiment behavior wilcoxon ( practices) acquired value $p<0,05$ and an increase in $163 \%$ between before and after he received treatment in form of sexual education booklet aimed early childhood.Drawing conclusions this research is education health booklets about the media can be one of an alternative health education in enhancing knowledge, attitude and your action in the provision of sexual education to early childhood.

Key words: booklets, knowledge, attitude the act of, sexual education

\begin{abstract}
Abstrak
Informasi tentang seksualitas sebaiknya didapatkan anak langsung dari orang tuanya, namun karena kurangnya pengetahuan orang tua serta kurangnya interaksi dan komunikasi antara orang tua dan anak menjadi faktor utama belum tersampaikannya pendidikan seksual sejak usia dini di lingkup keluarga. Informasi mengenai kesehatan seksual yang diberikan kepada anak bertujuan agar anak tidak memiliki pemahaman yang salah dan menjadi korban kekerasan seksual. Untuk dapat meningkatkan pengetahuan ibu diperlukan pendekatan pendidikan kesehatan dengan media cetak booklet yang memuat informasi pendidikan seksual untuk anak usia dini yang disajikan dalam tulisan dan gambar agar mudah dipahami dan pesan dapat dinikmati kapan saja tanpa menentukan waktu. Penelitian ini adalah studi pra-eksperimen menggunakan desain one group pretest- posttest, dilakukan di Kelurahan Kebon Waru wilayah kerja Kota Bandung dengan sampel sebanyak 34 ibu yang memiliki anak usia 3-6 tahun yang dipilih secara concecutive sampling. Perbedaan pengetahuan, sikap dan tindakan ibu sesudah mendapatkan booklet pendidikan seksual usia dini diukur menggunakan kuesioner. Analisis data dengan uji wilcoxon. Hasil penelitian menunjukan terdapat perbedaan yang signifikan dengan nilai $\mathrm{p}<0,05$ dengan peningkatan $30 \%$ pada skor pengetahuan sebelum dan sesudah pemberian perlakuan dengan booklet. Pada skor sikap terdapat peningkatan sebesar $11,42 \%$ dengan nilai $\mathrm{p}<0,05$ artinya terdapat perbedaan yang signifikan antara sebelum diberi perlakuan dengan setelah diberi perlakuan dengan booklet. Pada uji wilcoxon perilaku (praktik) didapatkan nilai $\mathrm{p}<0,05$ dan peningkatan $163 \%$ antara sebelum dan setelah diberi perlakuan berupa booklet pendidikan seksual anak usia dini. Simpulan penelitian ini adalah pendidikan kesehatan dengan media booklet dapat menjadi salah satu alternative pendidikan kesehatan dalam meningkatkan pengetahuan, sikap dan tindakan ibu dalam pemberian pendidikan seksual untuk anak usia dini.
\end{abstract}

Kata kunci: Booklet, Pengetahuan, Sikap, Tindakan, Pendidikan Seksual

\title{
PENDAHULUAN
}

UNICEF (2014) mengungkapkan bahwa sekitar 120 juta anak di seluruh dunia telah menjadi korban kekerasan seksual di bawah usia 20 tahun. Data lain dari Kementerian 
Email : pgrasyekhnuriati@gmail.com

P-ISSN: 2541-4658

E-ISSN: 2528-7427

Pemberdayaan Perempuan dan Perlindungan Anak (KPP-PA) menyebutkan bahwa prevalensi kekerasan terhadap anak yaitu 3,02\%. Hal ini berarti di antara 100 anak terdapat 3 anak yang mengalami kekerasan dan kekerasan seksual merupakan jenis kekerasan yang paling banyak ditemukan (Indanah, 2016). Pusat Pelayanan Terpadu Pemberdayaan Perempuan dan Anak (P2TP2A) di Jawa Barat, kasus kekerasan seksual anak mengalami peningkatan pada tahun 2016 hingga 2017 untuk kasus kekerasan seksual terhadap anak terjadi sekitar 346 kasus (Syahputra \& Arif, 2017). Kota Bandung tercatat 130 kasus kekerasan perempuan dan anak. Kasus kekerasan seksual berdasarkan usia korban, terbanyak terjadi pada usia 6-12 tahun (33\%) dan terendah usia 0-5 tahun $(7,7 \%) .{ }^{4}$ Wilayah kerja Puskesmas Ibrahim Ajie Kota Bandung pada periode Januari-Mei 2017 terdapat 5 kasus kekerasan seksual terhadap anak usia dini, rata-rata pada usia 4-6 tahun (Puskesmas Ibrahim Ajie, 2017)

Orang tua mempunyai fungsi pendidik karena seorang anak pertama kali memperoleh pengetahuan dari orang tuanya terutama ibu, sebagai orang yang paling dekat dengan anak. Dengan demikian kepribadian seseorang terbentuk sebagai hasil perpaduan antara warisan sifat-sifat, bakat orang tua dan lingkungan pertama yang mula-mula memberikan pengaruh yang mendalam adalah keluarga sendiri. Peran orang tua sebagai pendidik harus mempunyai pengetahuan mengenai pendidikan seksual pada anak tentang pengenalan bagian organ-organ apa saja yang ada di dalam tubuhnya serta fungsinya, serta bagaimana cara merawat dan membersihkannya dan mengajarkan mereka bagaimana perbedaan cara buang air kecil pada laki-laki dan perempuan, pendidikan ini pun secara tidak langsung dapat mengajarkan anak untuk tidak sembarangan mengizinkan orang lain membersihkan alat kelaminnya (Sulistianingsih, Apri dan Widayati, 2016).

Hal ini sudah menjadi perhatian banyak orang, upaya yang dilakukan untuk pencegahan kekerasan seksual pada anak juga semakin gencar. Penelitian Zhang (W. Zhang, 2013). menyebutkan bahwa tingkat pengetahuan orang tua menjadi faktor yang mempengaruhi komunikasi dalam pemberian pendidikan kesehatan seksual pada anak. Sehingga anak-anak prasekolah tidak memiliki pengetahuan yang cukup baik dalam keterampilan perlindungan diri sebagai upaya pencegahan kekerasan seksual anak. Orang Perbedaan pengetahuan, sikap dan tindakan lbu Sesudah mendapatkan booklet Pendidikan Untuk Anak Usia Dini 
Email : pgrasyekhnuriati@gmail.com

P-ISSN: 2541-4658

E-ISSN: 2528-7427

tua perlu diberikan informasi mengenai pendidikan seksual pada anak dan cara berkomunikasi dengan anak-anak tentang pencegahan kekerasan seksual. Pike melakukan penelitian mengenai Teaching parents about child health using a practice booklet menjelaskan bahwa terdapat peningkatan yang signifikan pengetahuan orang tua yang mendapatkan booklet dalam memberikan pendidikan kesehatan pada anak (Pike L.A, 1980).

\section{METODE PENELITIAN}

Penelitian ini adalah studi pra-eksperimen menggunakan desain one group pretestposttest, dilakukan di Kelurahan Kebon Waru wilayah kerja Kota Bandung dengan sampel sebanyak 34 ibu yang memiliki anak usia 3-6 tahun yang dipilih secara concecutive sampling. Perbedaan pengetahuan, sikap dan tindakan ibu sesudah mendapatkan booklet pendidikan seksual usia dini diukur menggunakan kuesioner. Analisis data dengan uji wilcoxon.

\section{HASIL PENELITIAN}

\section{Perbedaan pengetahuan ibu sesudah mendapatkan booklet pendidikan seksual} anak usia dini.

Tabel 1 Skor pengetahuan ibu sesudah mendapatkan booklet pendidikan seksual anak usia dini

\begin{tabular}{|c|c|c|c|}
\hline \multirow{2}{*}{ Pengetahuan } & \multicolumn{2}{|c|}{ Booklet $(\mathrm{n}=34)$} & \multirow[t]{2}{*}{ Nilai p } \\
\hline & Pre-test & Post-test & \\
\hline Rerata (SD) & $9,23(4,05)$ & $12,62(2,86)$ & \\
\hline Median & 10 & 13 & $0,000 *$ \\
\hline Rentang & $0-17$ & $4-17$ & \\
\hline Peningkatan (\%) & \multicolumn{2}{|c|}{30} & \\
\hline
\end{tabular}

Berdasarkan tabel 1 dari 34 sampel yang di uji terdapat peningkatan pengetahuan sebelum dan sesudah diberikan pendidikan kesehatan meningkat sebesar 30\%. Pada uji wilcoxon skor pengetahuan antara sebelum diberi perlakuan dengan sesudah diberi berupa Booklet menunjukkan nilai $\mathrm{p}<0,05$ artinya terdapat perbedaan signifikan skor pengetahuan sesudah diberikan perlakuan berupa Booklet. 
Email : pgrasyekhnuriati@gmail.com

P-ISSN: 2541-4658

E-ISSN: 2528-7427

\section{Perbedaan sikap ibu sesudah mendapatkan booklet pendidikan seksual anak usia} dini.

Tabel 2 Skor sikap ibu sesudah mendapatkan booklet pendidikan seksual anak usia dini

\begin{tabular}{lccc}
\hline \multirow{2}{*}{ Sikap } & \multicolumn{2}{c}{ Booklet $(\mathbf{n = 3 4 )}$} & Nilai p \\
\cline { 2 - 3 } & Pre-test & Post-test & \\
\hline Rerata (SD) & $35,76(6,52)$ & $39,71(5,10)$ & $0,034^{*}$ \\
Median & 35 & 39 & \\
Rentang & $17-49$ & $33-49$ & \\
\hline Peningkatan (\%) & \multicolumn{3}{c}{11,42} \\
\hline *)wilcoxon
\end{tabular}

Berdasarkan tabel 2 dari 34 sampel yang di uji terdapat peningkatan sikap sebelum dan sesudah diberikan pendidikan kesehatan meningkat sebesar 11,42\%. Pada uji wilcoxon skor sikap antara sebelum diberi perlakuan dengan sesudah diberi berupa Booklet menunjukkan nilai $\mathrm{p}<0,05$ artinya terdapat perbedaan signifikan skor sikap sesudah diberikan perlakuan berupa Booklet.

\section{Perbedaan tindakan ibu sesudah mendapatkan booklet pendidikan seksual anak} usia dini.

Tabel 3 Skor tindakan ibu sesudah mendapatkan booklet pendidikan seksual anak usia dini

\begin{tabular}{lccc}
\hline \multirow{2}{*}{ Perilaku (Praktik) } & \multicolumn{2}{c}{ Booklet $(\mathbf{n = 3 4})$} & Nilai p \\
\cline { 2 - 3 } & Pre-test & Post-test & \\
\hline Rerata (SD) & $5,35(2,60)$ & $12,70(3,01)$ & \\
Median & 5,5 & 14,5 & $0,000^{*}$ \\
Rentang & $1-10$ & $6-15$ & \\
\hline Peningkatan (\%) & \multicolumn{3}{c}{163} \\
\hline *)Wilcoxon
\end{tabular}

Berdasarkan tabel 3 dari 34 sampel yang di uji terdapat peningkatan tindakan sesudah diberikan pendidikan kesehatan meningkat sebesar 163\%. Pada uji wilcoxon skor tindakan antara sebelum diberi perlakuan dengan sesudah diberi berupa Booklet menunjukkan nilai $\mathrm{p}<0,05$ artinya terdapat perbedaan signifikan skor tindakan antara sesudah diberikan perlakuan berupa Booklet. 


\section{PEMBAHASAN}

\section{Perbedaan pengetahuan ibu sesudah mendapatkan booklet pendidikan seksual anak usia dini}

Hasil penelitian pada table 1 pengetahuan antara sebelum diberi perlakuan dengan sesudah diberi berupa Booklet menunjukkan perbedaan yang signifikan. Booklet merupakan salah satu media pendidikan kesehatan yang memungkinkan disajikannya informasi secara lebih terperinci dibandingkan leaflet, namun lebih ringkas dibandingkan buku. Pemanfaatan media booklet yang menyajikan informasi tentang kesehatan reproduksi khususnya tentang pendidikan seksual untuk anak usia dini yang mencakup pengenalan nama anggota tubuh, penggunaan busana yang baik, memperkenalkan anggota keluarga, kerabat dan tetangga, serta cara merawat dan menjaga tubuh termasuk ketrampilan menjaga diri dari ancaman kekerasan seksual yang disajikan secara terperinci dan ringkas dalam penelitian ini, dapat memudahkan responden dalam mempelajari materi sehingga memungkinkan terjadinya penyerapan informasi secara lebih baik.

Efektivitas penyampaian informasi dalam media cetak tidak hanya terletak pada muatan informasinya saja namun ditentukan oleh penggunaan gambar-gambar untuk memperjelas informasi yang terkandung di dalamnya. Penggunaan media akan lebih menarik apabila menampilkan gambar-gambar yang relevan walaupun sifatnya sederhana. Hal ini bertujuan untuk membangkitkan minat baca responden sehingga akan berdampak positif terhadap pemahaman tentang topik yang disampaikan. Booklet pendidikan seksual anak usia dini yang digunakan dalam penelitian ini menyajikan informas tentang pengenalan nama anggota tubuh, penggunaan busana yang baik, memperkenalkan anggota keluarga, kerabat dan tetangga, serta disertai gambar yang berhubungan dengancara merawat dan menjaga tubuh termasuk ketrampilan menjaga diri dari ancaman kekerasan seksual yang dapat menarik minat responden untuk mempelajari booklet tersebut lebih jauh. Hal ini ditunjang dengan adanya pendapat bahwa tulisan dan gambar yang terdapat pada media pendidikan kesehatan walaupun bersifat statis namun mampu menyampaikan pesan secara visual sehingga mudah diserap oleh responden. 
Email : pgrasyekhnuriati@gmail.com

P-ISSN: 2541-4658

E-ISSN: 2528-7427

Hasil penelitian ini memperlihatkan bahwa adanya peningkatan pengetahuan sesudah diberikan pendidikan kesehatan reproduksi dengan media booklet pada ibu yang memiliki anak usia 3-6 tahun memberikan peluang untuk dilakukannya pemberian informasi pendidikan seksual pada anak usia dini sebagai upaya pencegahan kekerasan seksual khususnya pada anak usia dini di daerah penelitian.

\section{Perbedaan sikap ibu sesudah mendapatkan booklet pendidikan seksual anak usia dini}

Sikap merupakan kecenderungan potensial seorang individu untuk bereaksi terhadap suatu stimulus yang menghendaki adanya respon. Respon yang dinyatakan sebagai sikap tersebut timbul didasari oleh proses evaluasi dalam diri individu yang memberikan kesimpulan terhadap stimulus dalam bentuk nilai baik-buruk, positif-negatif, menyenangkan-tidak menyenangkan. Hai ini berarti bahwa sikap juga dapat dimaknai sebagai penilaian positif- negatif terhadap suatu objek. Sikap secara nyata menunjukan konotasi adanya kesesuaian reaksi terhadap stimulus tertentu. Ibu yang memiliki anak usia 3-6 tahun diharapkan dapat memiliki sikap positif yaitu bersedia memberikan pendidikan seksual pada anak usia dini setelah memperoleh informasi tentang pendidikan kesehatan reproduksi.

Hasil penelitian pada tabel 2 menunjukkan bahwa skor Sikap antara sebelum diberi perlakuan dengan setelah diberi berupa Booklet menunjukkan berbeda bermakna dengan nilai $\mathrm{p}<0.05$. Pemanfaatan media booklet dalam penelitian ini memungkinkan terjadinya proses pemindahan informasi yang memberikan pengetahuan baru pada responden. Terjadinya peningkatan pengetahuan dalam penelitian ini sebagaimana yang ditampilkan pada tabel 1 memiliki hubungan yang positif dengan terjadinya perbedaan sikap seperti yang ditampilkan pada tabel 2 hal ini membuktikan kebenaran dari teori bahwa pengetahuan mempengaruhi keputusan seseorang dalam menentukan sikapnya terhadap suatu objek. Pertimbangan ibu yang memberikan pendidikan seksual pada anaknya yang berusia 3-6 tahun yang berisiko mendapat kekerasan seksual dipengaruhi oleh pengetahuan mereka tentang kesehatan reproduksi khususnya tentang pendidikan seksual untuk anak usia dini.

Berdasarkan hasil penelitian ini dapat disimpulkan bahwa sikap terhadap pemberian Perbedaan pengetahuan, sikap dan tindakan lbu Sesudah mendapatkan booklet Pendidikan Untuk Anak Usia Dini 
Email : pgrasyekhnuriati@gmail.com

P-ISSN: 2541-4658

E-ISSN: 2528-7427

pendidikan seksual untuk anak usia dini ditentukan oleh sejauh mana individu mempertimbangkan secara positif atau negatif untuk memberikan pendidikan seksual pada anaknya sehingga menjadi yakin bahwa dengan memberikan dan menerapkan hal tersebut dapat mencegah kekesaran seksual yang mungkis saja dapat terjadi pada anaknya.

\section{Perbedaan tindakan ibu sesudah mendapatkan booklet pendidikan seksual anak usia dini}

Perilaku manusia merupakan hasil daripada segala macam pengalaman serta interaksi manusia dengan lingkungannya yang terwujud dalam bentuk pengetahuan, sikap dan tindakan. Tindakan yaitu apa yang dilakukan oleh responden terhadap hal yang terkait dengan kesehatan. Pengukuran tindakan adalah mengukur praktek, tindakan, atau kegiatan yang dilakukan oleh responden tentang hal-hal yang terkait dengan pemeliharaan atau peningkatan kesehatannya (Notoatmodjo, 2012).

Pemberian pendidikan seksual pada anak usia dini dilihat dari jawaban ibu dalam kuesioner tindakan yang diukur secara tidak langsung dengan metode "recall" atau mengingat kembali terhadap apa yang telah dilakukan responden selama 4 minggu. Tabel 3 menunjukkan hasil bahwa terdapat perbedaan tindakan antara sebelum dan setelah diberikan pendidikan kesehatan dengan media booklet. Berdasakan data hasil penelitian adanya perbedaan tindakan setelah diberikan pendidikan kesehatan dengan booklet pendidikan seksual anak usia dini mengindikasikan bahwa responden memiliki kesadaran yang baik untuk menghindari dampak negatif dari anak usia dini yang tidak mengetahui pendidikan seksual yang tepat. Pendidikan kesehatan dengan booklet ini juga merupakan upaya preventif dari kekerasa seksual yang mungkin saja dapat dialami oleh anak mereka. Salah satu program kesehatan untuk meningkatkan pengetahuan dan merubah persepsi serta praktik kearah positif adalah melalui pendidikan kesehatan (Fitriani. S, 2011)

Booklet merupakan salah satu media pendidikan kesehatan yang salah satu kelebihannya adalah memungkinkan terjadinya pengulangan proses pembelajaran. Booklet memungkinkan seorang individu untuk mempelajari kembali isi materi yang pernah disampaikan. Setiap individu memiliki kapasitas memori yang berbeda. Pengetahuan merupakan salah satu cara untuk meningkatkan kapasitas memori tersebut. Semakin banyak Perbedaan pengetahuan, sikap dan tindakan lbu Sesudah mendapatkan booklet Pendidikan Untuk Anak Usia Dini 
Email : pgrasyekhnuriati@gmail.com

P-ISSN: 2541-4658

E-ISSN: 2528-7427

pengetahuan yang dimiliki seseorang maka akan semakin baik proses pengorganisasian dan penyerapan informasi yang terjadi dalam dirinya. Salah satu cara agar penyampaian informasi dapat terjadi dengan lebih efisien dalam meningkatkan kapasistas memori kerja adalah pengulangan. Para ahli menyampaikan bahwa suatu informasi dapat tersimpan lama dalam memori seseorang jika disampaikan secara berulang-ulang (Kholid. A, 2012).

Media booklet pendidikan seksual anak usia dini yang digunakan pada penelitian ini memberikan stimulus yang berulang-ulang serta penekanan terhadap gambaran yang nyata yang disampaikan melalui gambar dan pesan yang terkandung di dalam booklet telah berdampak terhadap perubahan sikap positif ibu yang pada akhirnya mempengaruhi perilaku ibu dalam praktiknya memberikan pendidikan seksual kepada anaknya yang berusia 3-6 tahun. Paramastri (Paramastri, 2011) menyatakan bahwa orang tua harus berperan aktif dalam memberikan bimbingan tentang pendidikan seksual melalui komunikasi dalam keluarga, hal ini meminimalisir tidak terjadinya kesalahpahaman pengetahuan dan kesalahan dalam memberikan informasi tentang pendidikan seksual pada anak usia dini. Berdasarkan beberapa penjelasan tersebut dapat disimpulkan bahwa pendidikan kesehatan dengan menggunakan booklet mempunyai dampak dan pengaruh terhadap perubahan pengetahuan, sikap dan perilaku dalam hal ini praktik ibu dalam pemberian pendidikan seksual untuk anak usia dini. Karena hal tersebut sesuai dengan tujuan yaitu tujuan pendidikan kesehatan bertujuan untuk merubah perilaku seseorang menjadi lebih baik.

\section{Keterbatasan Penelitian}

Penelitian ini menggunakan intervensi berupa booklet pendidikan seksual untuk anak usia dini yang bersumber dari jurnal dan kurikulum pendidikan anak usia dini. Booklet hanya dilakukan uji konten oleh pakar/ahli dan uji keterbacaan oleh responden saat uji validitas dan realiabilitas kuesioner, sehingga belum dilakukan uji validitas dan reliabilitas. Penelitian ini juga menggunakan metode pengukuran tindakan ibu secara tidak langsung sehingga peneliti tidak melihat secara langsung bagaimana ibu memberikan pendidikan seksual anak usia dini kepada anaknya. 


\section{SIMPULAN}

Berdasarkan hasil penelitian dan pembahsan dapat dibuat simpulan sebagai berikut:

1. Terdapat perbedaan pengetahuan ibu sesudah mendapatkan booklet pendidikan seksual anak usia dini.

2. Terdapat perbedaan sikap ibu sesudah mendapatkan booklet pendidikan seksual anak usia dini.

3. Terdapat perbedaan tindakan ibu sesudah mendapatkan pendidikan seksual anak usia dini.

Adapun penulis memberikan saran terhadap pihak-pihak yang berkaitan dengan

hasil penelitian ini yakni:

1. Dilakukan uji validitas dan reliabilitas booklet agar dapat sesuai berdasarkan keilmuan, pendapat dan persepsi pengguna booklet baik dari aspek desain visual, keilmuan maupun kemudahan pembaca dalam menyerap informasi yang disajikan dalam booklet.

2. Diperlukan penelitian lanjutan dengan desain quasi eksperimen menggunakan kelompok kontrol sebagai pembanding kelompok intervensi dengan jangka waktu evaluasi pengetahuan, sikap dan perilaku (tindakan) yang lebih lama.

3. Diharapkan media booklet dalam penelitian ini dapat digunakan sebagai media pendidikan kesehatan pada ibu yang memiliki anak usia 3-6 tahun.

4. Diharapkan peneliti bekerjasama dengan pemerintah dan lembaga terkait seperti P2TP2A, KPAI dan tenaga kesehatan sehingga dapat menggunakan booklet dalam penelitian ini sebagai media pendidikan kesehatan.

\section{DAFTAR PUSTAKA}

Indanah. (2016). Pelecehan sexual pada anak. JIKK. Januari;7(1):16-23.

Diah Utami. (2014). Kekerasan Seksual pada Anak Meningkat. CNN Indonesia: Senin, 01 September 10:57 WIB. (diunduh September 2017). https://www.cnnindonesia.com/nasional/20140901105717-12-2120/kekerasanseksual-pada-anak-meningkat/

Perhimpunan Dokter Forensik Indonesia Prosiding Pertemuan Ilmiah Tahunan 2017. ISBN 978-602-5027-0-9. P; 8-13. 
Komisi Nasional Anti kekerasan Terhadap Perempuan. Labirin Kekerasan terhadap Perempuan: Dari Gang Rape hingga Femicide, Alarm bagi Negara untuk Bertindak Tepat. Lembar Fakta Catatan Tahunan (CATAHU) Komnas Perempuan Tahun 2017. Jakarta, 7 Maret 2017:1-4.

Puskesmas Ibrahim Ajie Kota Bandung. Periode data Januari - Mei 2017.

Saragih, Rahmat Sah. (2014). Membangun paradigma optimalisasi kompetensi mahasiswa melalui pendidikan kesehatan reproduksi dan seksual. Esai Kritis OIMUI.

Sulistianingsih, Apri dan Wahyu Widayati. (2016). Hubungan Pengetahuan dengan Perilaku Ibu Memberikan Pendidikan Seks pada Anak. Bidan Prada: J Ilmiah Kebidanan. Desember; 7(2):34-43.

Safita, Reny. (2013). Peranan orang tua dalam memberikan pendidikan seksual pada anak. J Edu-Bio Vol. 4:32-40.

Selvira Azrina. (2017). Pengetahuan ibu tentang pendidikan seks anak usia 3-6 tahun di wilayah kerja puskesmas Ibrahim adjie kota bandung. J Masada.

Dwi Ario Fajar, Sutanto, Ribut A. (2014). Strategi optimalisasi pendidikan seks usia dini di PAUD dalam menanggulangi pelecehan seks terhadap anak di Pekalongan. J Litbang Pekalongan :40-52

Nurhasmah Wini. (2015). Implementasi pendidikan seksual untuk anak usia dini. J UPI Edu;.

Imanda Kartika Putri.(2012). Faktor-faktor yang berhubungan dengan perilaku pemberian pendidikan seks untuk anak oleh orangtua siswa Madrasah Ibtidaiyah Hayatul Islamiyah Depok. J Masada.

W. Zhang et al. (2013). Young children's knowledge and skills related to sexualabuse prevention: A pilot study in Beijing, China. Child Abuse \& Neglect 37: 623- 630.

Pike L.A. (1980). Teaching parents about chid health using a practice booklet. Journal of the Royal Collage of General Practitioners, 30, 517-519.

Slavin RE.(2011). Teori Pendidikan: Teori dan Praktik. Kesembilan ed. Jakarta: Indeks; :215-71.

Aksi Cepat Tanggap. Leaflet Aku Mandiri (Anak Bisa Menjaga Diri). ACT dan KPAI. Jakarta: 2017. 
Homepage: www.syekhnurjati.ac.id/jurnal/index.php/awlady

Email : pgrasyekhnuriati@gmail.com

P-ISSN: 2541-4658

E-ISSN: 2528-7427

Setiawati S., Dermawan AC.(2008). Proses Pembelajaran Dalam Pendidikan Kesehatan. Jakarta: Trans Info Media; 2008:31-60

Joshi M.A. Ahirrao A. Effectiveness of Information Booklet on Knowledge About Disaster Preparedness. Journal of Communication. 2011;1(1):7-9.

Prince J. A Study to Develop and Evaluate The Effectiveness of Information Booklet on Emergency Contraception in Terms of Knowladge of Women and To Seek Its Reletionship with Factors in Selected Residential Apartement in Andra Pradesh. Journal of Biology, Agricuture and Healthcare. 2012;2(11):32-41.

Farudin A. Perbedaan Efek Konseling Gizi dengan Media Leaflet dan Booklet terhadap tingkat Pengetahuan, Asupan Energi dan Kadar Gula darah Pasien Diabetes Melitus di RSUD Dr. Moewardi Surakarta. J UNSFG. 2011

Paramastri Ira, J.E. Prawitasari, Yayi Suryo Prabandari, Endang Ekowarni. Buklet sebagai media pencegahan terhadap kekerasan seksual pada anak-anak. J Kesehatan Masyarakat Nasional. 2011 Oktober;6(2):77-84.

Gehan Mohammed Diab, Sohair M. Mabrouk. The effect of guidance booklet on knowledge and attitudes of nurses regarding disaster preparedness at hospitals. Journal of Nursing Education and Practice 2015;5(9). DOI: 10.5430/jnep.v5n9p17.

Notoatmodjo S. Kesehatan Masyarakat: Imu dan Seni. Jakarta: Rineka Cipta; 2011:109-167

Fitriani, S. Promosi Kesehatan. Yogyakarta: Graha Ilmu; 2011

Nurrasyidah. Pengaruh penerapan booklet kunjungan pada akseptor KB suntik 3 bulan terhadap pengetahuan, sikap dan ketepatan waktu kunjungan ulang. J IJMC; 2016

Rustan S. layout, Dasar \& penerapannya. Jakarta: Gramedia Pustaka Utama; 2010

Budiman AR. Kapita Seleekta Kuesioner; Pengetahuan dan Sikap dalam Penelitian Kesehatan. Taksonomi Domain Pengetahuan. Jakarta: EGC; 2007:43-56.

Nesi Novita YF. Promosi Kesehatan Dalam Pelayanan Kebidanan. Prinsip Perubahan Perilaku. Jakarta: Salemba Medika; 2013:73-101.

Notoatmodjo. Promosi Kesehatan dan Perilaku Kesehatan. Jakarta: Rineka Cipta; 2012

Kholid A. Promosi Kesehatan dengan pendekatan Teori Perilaku, Media dan Aplikasinya. Jakarta: Rajawali Pers; 2012 
Homepage: www.syekhnurjati.ac.id/jurnal/index.php/awlady

Email : pgrasyekhnuriati@gmail.com

P-ISSN: 2541-4658

E-ISSN: 2528-7427

Mubarak Wahit Iqbal. Promosi Kesehatan untuk Kebidanan. Jakarta: Salemba Medika; 2011

Azwar S. Sikap Manusia, teori dan Pengukurannya. Yogyakarta:Pustaka Pelajar; 2013

Fatmah. Teori dan Penerapan Media Komunikasi. Jakarta: Erlangga; 2014

Baharits, Adnan Hasan Shalih. Pengetahuan dalam Pendidikan Seks Education. Jakarta: Gema Insani Press. 2012.

Nawita, Muslik. Bunda, Seks itu Apa? : Bagaimana Menjelaskan Seks pada Anak. Bandung: Yrama Widya; 2013.

Handayani, Alva dan Aam Amiruddin. Anak Anda Bertanya Seks?: Langkah Mudah Menjawab Pertanyaan Anak tentang Seks. Khazanah Bandung: 2008.

Pramitha.,dkk. Serunya Dunia Anak Usia Dini. Jakarta: Panda Media; 2015:143-161.

Tri Endang Jatmikowati, Ria Angin, dan Ernawati. Model Dan Materi Pendidikan Seks Anak Usia Dini Perspektif Gender Untuk Menghindarkan Sexual Abuse FKIP Universitas Muhammadiyah Jember. J Cakrawala Pendidikan. 2015 Oktober;34(3):434-448.

MS.Sumantri. Model Pengembangan Ketrampilan Motorik Anak Usia Dini. Dinas Pendidikan; Jakarta: 2005:11

Dahlan MS. Besar Sampel dan Cara Pengambilan Sampel Dalam Penelitian Kedokteran dan Kesehatan. Ed-3. Jakarta: Salemba Medika; 2010.

Bertens K. Etik Biomedis. Yogyakarta: Kanikus; 2011

Wanodya Puspitaningrum. Pengaruh Media Booklet Terhadap Pengetahuan Dan Sikap Remaja Putri Terkait Kebersihan Dalam Menstruasi. J Kesehatan Masyarakat 2017 Oktober;5(4):274-281

Megayana Mareta. Pengaruh Edukasi Kesehatan Prakonsepsi dengan Buklet Terhadap Ketidaksiapan Kehamilan Calon Pengantin Berisiko di Kota Surakarta. J IJMC. 2018

Komala L., Novianti E., dan Subekti P. Strategi Pemilihan Media Promosi Kesehatan dalam Penanggulangan HIV/AIDS di Kabupaten Garut. Actadium A. 2014;1(2):34-43.

Zulaekah S. Efektifitas Pendidikan Gizi dengan Media Booklet Terhadap Pengetahuan Gizi Anak SD. J. Kesehatan Masyarakat. 2012; 7(2): 121-128 
Lopez LM, Steiner M, Grimes DA, Hilgenberg D, Schulz KF. Strategies for communicationting contraceptiveness. Chohrane Database of Systematic Reviews. 2013(4).

Vitrilina Hutabarat. Pengaruh Pendidikan Kesehatan Menggunakan Booklet terhadap peningkatan Pengetahuan dan Kepatuhan Minum ARV. J IJMC. 2018

Puspitasari A.W. Analisis Efektifitas Pemberian Booklet Obat Terhadap Tingkat Kepatuhan Ditinjau dari kadar Haemoglobin Terglikasi (HbAlc) dam Morisky Medication Adherence Scale (MMAS)-8 pada pasien Diabetes MelitusTipe 2 di Puskesmas Bhakti Jaya Kota Depok; 2012 